\title{
Virtual Screening of Dipeptidyl Peptidase IV Inhibitors from Zinc Database
}

\author{
Phani Kumar \\ Yadla, SRF, \\ C R Rao AIMSCS
}

\author{
Allam Appa Rao, \\ Director, C R Rao \\ AIMSCS
}

\author{
A. Swaroopa \\ Rani, PhD. \\ Coordinator $R$ \& D, \\ JNTU H
}

\author{
M. Naresh Babu, \\ $\mathrm{PhD}$. \\ Assistant Professor, \\ C R Rao AIMSCS
}

\begin{abstract}
Dipeptidyl peptidase IV (DPP IV) is a serine exopeptidase that cleaves X-proline dipeptides from the $\mathrm{N}$ terminus of polypeptides. Dipeptidyl peptidase IV enzyme activity has been implicated in the regulation of the biological activity of multiple hormones and chemokines, including the insulinotropic peptides glucagon-like peptide-1 (GLP1) and glucose-dependent insulinotropic polypeptide (GIP). Hence, DPP IV has an important role in glucose homeostasis, and was established as a potential target for therapy in type II diabetes. Hence, there is a need to identify the most potent compound that would specifically target DPP IV.

Initially, protein structure DPP IV was extracted from Protein Data Bank by performing a search resulted in 86 hits. They are filtered based on the presence of X-ray diffraction as the experimental method, between 2.0 and $2.5 \mathrm{~A}^{\circ}$ resolution and with bound ligands. From the result, presence of breaks in the protein are checked and based on Ramchandran plot, 2QOE was selected as the protein target. Further analysis was carried to screen compounds from ZINC database, on Lipinski's rule of 5 using the virtual screening software like eHiTS.
\end{abstract}

Key words:DPP IV, eHiTS, ZINC database, PDB.

\section{INTRODUCTION}

Dipeptidyl Peptidase IV (DPPIV) is a clinically validated target for type-2 diabetes [1] and belongs to a family of peptidases. It has unique post-proline cleavage specificity mechanism with $110-\mathrm{kDa}$ glycoprotein that is expressed on numerouscell types and has multiple biological functions [2, $3]$. The membranebound glycoprotein dipeptidyl peptidase IV is a unique multifunctional protein, acting as receptor, binding and proteolytic molecule. The crystal structure reveals a 2-2-2 symmetric tetrameric assembly which depends on the nativelyglycosylated propeller blade IV [4]. The crystal structure indicates that tetramerization of DPP IV is a key mechanism to regulate its interaction with other components [5].

Dipeptidyl-peptidase IV (DPPIV or CD26) is a homodimeric type II membrane glycoprotein in which the two monomers are subdivided into a $\beta$-propeller domain and an $\alpha / \beta$. hydrolase domain. The 3.0- $\AA$ resolution crystal structure of the complex formed between human DPPIV and bovine ADA presented here shows that each $\beta$-propeller domain of the DPPIV dimer binds one ADA. At the binding interface, two hydrophobic loops protruding from the $\beta$-propeller domain of DPPIV interact with two hydrophilic and heavily charged $\alpha$ helices of ADA, giving rise to the highest percentage of charged residues involved in a protein-protein contact reported thus far. Additionally, four glycosides linked to Asn229 of DPPIV bind to ADA. ADA binding to DPPIV could regulate this adhesion, as it would abolish tetramerization [6]. The crystal structure of CD26 was studied by Engel et al (2003) to reveal its functional regulation and enzymatic mechanism [7].

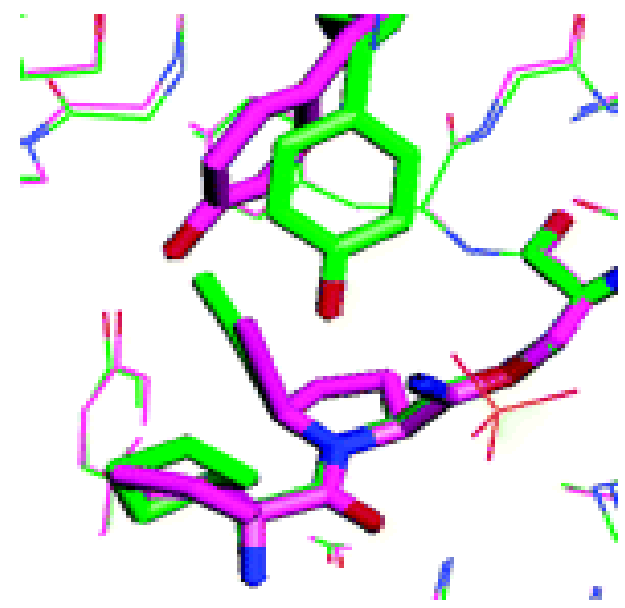

Figure 1: Crystal Structures of DPP-IV (CD26) from Rat Kidney [8]

\subsection{Complex mechanisms of DPP-IV inhibitor action}

The stabilization of GLP-1 as a result of DPP-IV inhibition in the gastrointestinal tract, and the effects of GLP-1 on sensory nerves (described by Holst and Deacon in the present issue [9]) are plausible explanations. Furthermore, DPP-IV inhibitors stabilise not only GLP-1, but also other insulinotropic hormones and neuropeptides. Only one-third to one-half of the postprandial GLP-1 in the plasma of healthy subjects and type 2 diabetic patients consists of active GLP-1, the rest being the inactive fragment formed by truncation [10]. During treatment with a DPP-IV inhibitor, the relative proportion of the active form is clearly increased 11].

DPP-IV-truncated GLP-1 and GIP act as receptor antagonists $[12,13]$, thereby decreasing the direct effects of native peptides and possibly desensitizing the receptors (as observed after the DPP-IV truncation of chemokines [14]). In other physiological systems, increased receptor stimulation/internalization results in the compensatory up regulation of peptide synthesis/secretion. Feedback mechanisms might be influenced by the ratio of active/intact GLP-1, which is increased when DPP-IV is inhibited [15]. 


\section{METHODOLOGY}

\subsection{Criteria used to select proteins for Virtual Screening}

When the DPP IV was searched in the Protein Data Bank about 86 Structural Hits were found. Out of these hits, entries were selected based on

- It should contain a ligand(s)

- Structure should be determined by X-ray diffraction.

All the proteins were checked for their score and RMSD values. 2 I78 has high score and low RMSD value and was thus selected for the screening analysis. Screening based on $2 \mathrm{I78}$ bound ligand structure was performed onZINC database using different criteria. Further docking studies were carried out using eHits with the molecules from ZINC database against 2I78.

\subsection{Criteria used to search ZINC Database}

There must be some valid criteria to screen huge library of compounds. Complete structure of DPP IV 2I78 bound ligand drawn using a tool available in ZINC database.No similar structures are identifiedin ZINC database.For the similar ligandswe perform the search operation using the properties of the ligand on ZINC database using different search criteriaviz Lipinski Rule of 5, Molecular Weight in between 303-407 and 410-450

Based on "Lipinski rule of 5
a) $\log \mathrm{p}<5$.
b) Molecular weight $<500$.
c) Rotatable bonds $(\mathrm{FB})<10$.
d) Hydrogen bond acceptor $<10$.
e) Hydrogen bond donor $<5$.

\section{RESULTS AND DISCUSSIONS}

2I78 ligand structure was drawn in java editor available in FAF drugs web page and the ligand associated properties were identified shown in Table 1 using ADME-Tox (Poor Absorption, Distribution, Metabolism, Elimination (ADME) or toxicity) filtering for small compounds.

Table 1: 2 I78 bound Ligand Properties

\begin{tabular}{|c|c|c|c|c|c|}
\hline Molecule & $\begin{array}{c}\text { Mol. } \\
\text { wt }\end{array}$ & HBA & HBD & LogP & $\begin{array}{c}\text { Rotatable } \\
\text { bonds }\end{array}$ \\
\hline $\begin{array}{c}\text { 2I78 } \\
\text { Ligand }\end{array}$ & 448.2 & 6 & 2 & 4.23 & 4 \\
\hline
\end{tabular}

Where, HBA = Hydrogen bond acceptors, HBD = Hydrogen bond donors.

\section{SMILES String for 2I78:}

$\mathrm{NC} 3 \mathrm{CC}(\mathrm{C}(\mathrm{O})[\mathrm{N}+] 1=\mathrm{CCN} 2 \mathrm{C}(=\mathrm{C} 1) \mathrm{N}=\mathrm{NC} 2 \mathrm{C}(\mathrm{F})(\mathrm{F}) \mathrm{F}) \mathrm{CCC} 3 \mathrm{c} 4$ $\operatorname{cc}(\mathrm{F}) \mathrm{c}(\mathrm{F}) \mathrm{cc} 4 \mathrm{~F}$

ZINC database was searched for the ligands for $2 \mathrm{I} 78$ using different criteria are shown in Figure 2, Figure 3 and Figure 4.

\subsection{ZINC DATABASE SEARCH}

ANALYSIS-1 :

\begin{tabular}{|l|ccl|}
\hline & $\leq$ & Net charge & $\leq$ \\
\hline 1.0 & $\leq$ & xLogP & $\leq 5$ \\
\hline 6 & $\leq$ & Rotatable bonds & $\leq 10$ \\
\hline 2 & $\leq$ & \# H-donors & $\leq 5$ \\
\hline 6 & $\leq$ & \# H-acceptors & $\leq 10$ \\
\hline & $\leq$ & Polar desolvation & $\leq$ \\
\hline & $\leq$ & Apolar desolvation: & $\leq$ \\
\hline & $\leq$ & Polar surface area: & $\leq$ \\
\hline 407 & $\leq$ & Molecular weight & $\leq 500$
\end{tabular}

Figure 2: Search ZINC using Lipinski Rule of 5

RESULT: From the above query 64720 hits are resulted from the first analysis. So the criteria have been changed to further filter the molecules by taking the averages into consideration and the succeeding values of the averages are taken.

\subsection{ZINC DATABASE SEARCH} ANALYSIS-2:

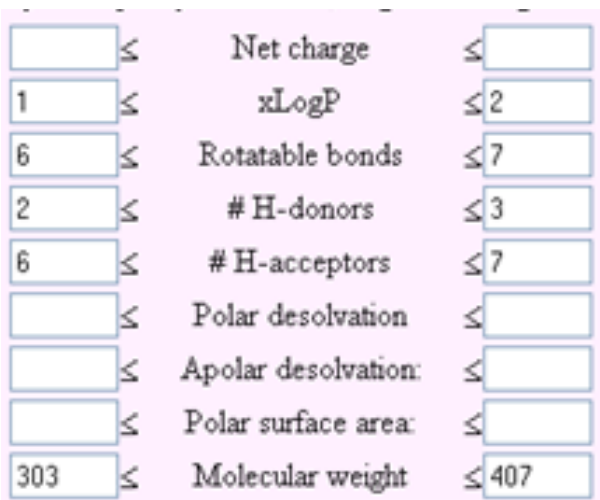

Figure 3: Search ZINC using the MW between 303 - 407

RESULT: Totally 33000 hits were obtained in the second analysis. So the criteria have been changed to further filter the molecules by taking the molecular weight between 410 and 450 because more hits are observed for a molecular weight range 409-410.

\subsection{ZINC DATABASE SEARCH}

ANALYSIS-3:

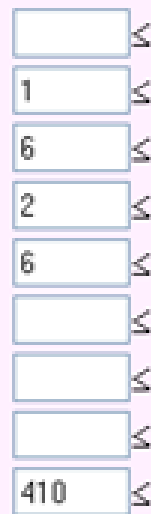

Net charge
xLogP
Rotatable bonds
\# H-donors
\# H-acceptors
Polar desolvation
Apolar desolvation:
Polar surface area:
Molecular weight

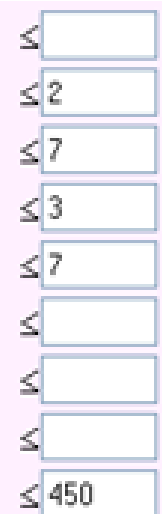

Figure 4: Search ZINC using the MW between 410 - 450 
RESULT: Totally 2900 hits were obtained in the third analysis and are considered for screening and evaluation studies.

All these molecules are run in ehits software using CheVi as front end and the results are recorded.

From the analysis, the best molecule was shown in Table 2.

Table 2 :eHits score of ZINC0648847

\begin{tabular}{|l|l|l|}
\hline S.No & ZINC ID & $\begin{array}{l}\text { e-hits } \\
\text { score(kcal/mol) }\end{array}$ \\
\hline 1 & ZINC0648847 & -4.908 \\
\hline
\end{tabular}

Original co crystalized and ZINC0648847 ligands are shown in Figure 5 and Figure 6

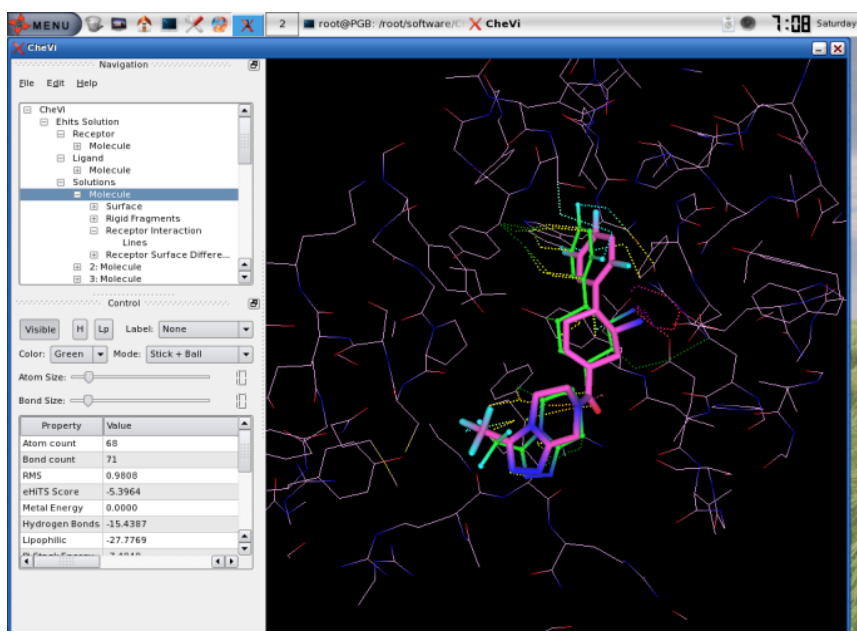

Figure 5: 2I78 original ligand superimposed image showing score of $\mathbf{- 5 . 3 9 6} \mathbf{~ k c a l} / \mathbf{m o l}$.

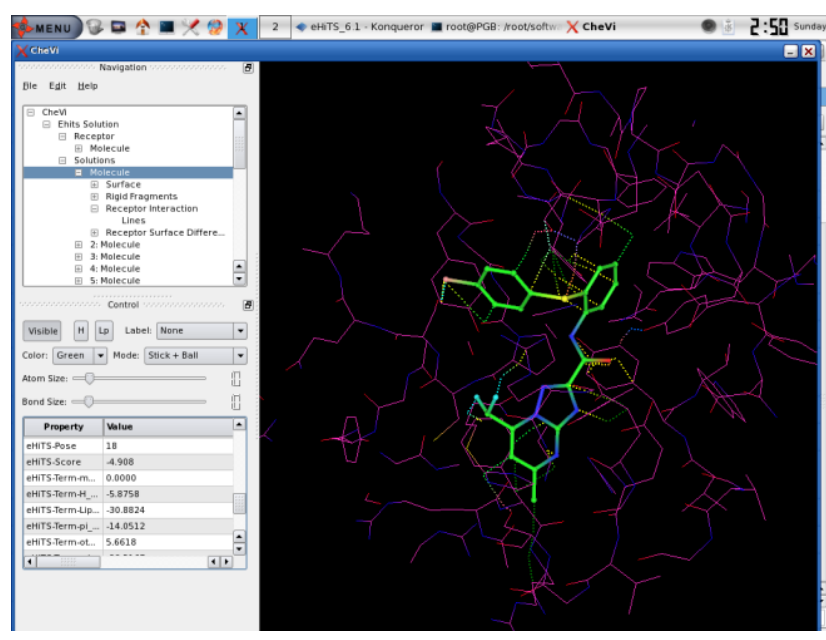

Figure 6: ZINC0648847 ligand showing e-hits score of $-4.908 \mathrm{kcal} / \mathrm{mol}$.

\section{ZINC0648847:}

The best molecule score was $-4.908 \mathrm{kcal} / \mathrm{mol}$ of ZINC0648847. Further optimization of this molecule resulted in a high score of $-5.420 \mathrm{kcal} / \mathrm{mol}$. This ligand with about 24 interactions and the Lipinski data are: $\mathrm{H}$-bond donors $1, \mathrm{H}-$ bond acceptor 6 , molecular weight $445.882, \log P \quad 4.65$ and the number of rotatable bonds are 5 respectively. From the interaction list, individual interactions between atomic coordinates of 2 I78 active site residues and ZINC ligand displayed the high score for 23rd interaction showing PHE357 residue $\mathrm{CZ}$ atom interaction with Fluorine ligand. This was mainly due to pi electron of an aromatic ring and lone electron pair of a halogen atom $(\mathrm{F}, \mathrm{Cl}, \mathrm{I})$ of $2 \mathrm{I} 78$. The best interaction from 24 interacting atoms between receptor and ligand of ZINC0648847 was:

Receptor SPT [16] Pi electron of an aromatic ring Ligand SPT[21] Lone electron pair of a halogen atom $(\mathrm{F}, \mathrm{Cl}, \mathrm{I})$

Receptor angle $\quad 12.60$

Ligand angle $\quad 25.51$

Dihedral angle $\quad 160.74$

Distance $\quad 4.3955$

Score $\quad-2.0144$

Receptor atom Index: 133 Residue: CZ PHE-357 Type $\mathrm{C}$

Ligand atom Index: 29 Type: $F$

Further, the ZINC0648847 was subjected to optimization process to optimize the interactions made by the ligand with active site residues of 2I78. Interestingly as expected the molecule showed high score $(-5.420 \mathrm{kcal} / \mathrm{mol})$ than the original ligand bound to $2 \mathrm{I} 78$ protein $(-5.396 \mathrm{kcal} / \mathrm{mol})$. The structure of ZINC0648847 is shown in Figure 7<smiles>O=C(Nc1ccccc1Sc1ccc(Cl)cc1)c1nc2nc([18OH])cc(C(F)F)n2n1</smiles>

Figure 7 : Structure of ZINC0648847

\section{CONCLUSION}

Virtual Screening procedure utilized in this study recognized the best molecule than the existing ligand for Dipeptidyl peptidase-IV. 2 I78 bound ligand properties based search in ZINC database resulted in 2900 molecules. 2 I78 bound cocrystallized ligand displayed e-hits score of $-5.396 \mathrm{kcal} / \mathrm{mol}$. Screening procedures carried out using selected criteria resulted in a best molecule represented by ZINC0648847 with e-hits score of $-4.908 \mathrm{kcal} / \mathrm{mol}$. Further optimization of this molecule resulted in a high score of $-5.420 \mathrm{kcal} / \mathrm{mol}$.

Therefore, this study states the importance of small molecule libraries and their use to enhance drug discovery process prior synthesis. As exemplified in this case, 2 I78 protein bound ligand, screening molecules and the criteria used to screen vast chemical library depends on the number of parameters such as Lipinski's rule of 5, volume and shape of ligand, number of attached groups on ligand, libraries and their search procedures, etc. This analysis states the importance of computational tools in screening ligand databases like ZINC and predicting the bioactive conformation of various ligands using eHiTS virtual screening software. 


\section{ACKNOWLEDGMENTS}

Mr. Phani Kumar Yadla, Dr. AllamAppaRao and Dr. M. NareshBabu would like to thank the Dept. of Science and Technology for their financial support (DST-CMS GoI Project No.SR/S4/MS:516/07 Dated 21.04.2008)

\section{REFERENCES}

[1] Barnett A (November 2006). "DPP-4 inhibitors and their potential role in the management of type 2 diabetes". Int. J. Clin. Pract. 60 (11): 1454-70. doi:10.1111/j.17421241.2006.01178.x. PMID 17073841

[2] Gupta R, Walunj SS, Tokala RK (2009) Emerging drug candidates of dipeptidyl peptidase IV (DPP IV) inhibitor class for the treatment of Type 2 Diabetes. Curr Drug Targets. 10: 71-87

[3] Orsakov, C. Diabetologia 1992, 35, 701.

[4] The crystal structure of dipeptidyl peptidase iv (cd26) reveals its functional regulation and enzymatic mechanism

http://www.pnas.org/cgi/content/abstract/0230620100v1

[5] Dipeptidyl peptidase iv and related enzymes in cell biology and liver disorders .gorrellmd. www.clinsci.org/cs/108/0277/cs1080277.html

[6] Wilhelm A. Weihofen $\neq$, Jiango Liu, Werner Reutter, Wolfram Saenger Crystal Structure of CD26/Dipeptidylpeptidase IV in Complex with Adenosine Deaminase Reveals a Highly Amphiphilic Interface , J. Biol. Chem., Vol. 279, Issue 41, 43330-43335, October 8, 2004.

[7] Engel, M.; Hoffmann, T.; Wagner, L.; Wermann, M.; Heiser, U.; Kiefersauer, R.; Huber, R.; Bode, W.; Demuth, H.-U.; Brandstetter,H ,Proc. Nat. Acad. Sci. 100: 5063-5068, 2003.

[8] Kenton L. Longenecker,Kent D. Stewart,David J. Madar,Clarissa G. Jakob,Elizabeth H. Fry, Sherwin Wilk, lChun W. Lin,Stephen J. Ballaron,Michael A. Stashko,Thomas H. Lubben,Hong Yong, Daisy Pireh,Zhonghua Pei,Fatima Basha,Paul E.
Wiedeman,Thomas W. von Geldern, James M. Trevillyan andVincent S. Stoll; Biochemistry,45 (24), $7474-7482,2006$.

[9] Holst JJ, Deacon CF (2005) Glucagon-like peptide-1 mediates the therapeutic actions of DPP-IV inhibitors. Diabetologia DOI 10.1007/S00125-005-1705-7.

[10] Vilsbøll T, Krarup T, Deacon CF, Madsbad S, Holst JJ (2001) Reduced postprandial concentrations of intact biologically active glucagon-like peptide 1 in type 2 diabetic patients. Diabetes 50:609613.

[11] Kieffer TJ, McIntosh CH, Pederson RA (1995) Degradation of glucose-dependent insulinotropic polypeptide and truncated glucagon-like peptide 1 in vitro and in vivo by dipeptidyl peptidase IV. Endocrinology 136:3585-3596.

[12] Knudsen LB, Pridal L (1996) Glucagon-like peptide-1(9-36) amide is a major metabolite of glucagon-like peptide-1-(7-36) amide after in vivo administration to dogs, and it acts as an antagonist on the pancreatic receptor. Eur J Pharmacol 318:429-435.

[13] Gault VA, Parker JC, Harriott P, Flatt PR, O ${ }^{8}$ Harte FP (2002) Evidence that the major degradation product of glucose-dependent insulinotropic polypeptide, $\operatorname{GIP}(3-$ 42 ), is a GIP receptor antagonist in vivo. J Endocrinol 175:525-533.

[14] Ludwig A, Schiemann F, Mentlein R, Lindner B, Brandt E (2002) Dipeptidyl peptidase IV (CD26) on T cells cleaves the CXC chemokine CXCL11 (I-TAC) and abolishes the stimulating but not the desensitizing potential of the chemokine. J LeukocBiol 72:183-191.

[15] Proost P, Schutyser E, Menten P et al (2001) Aminoterminal truncation of CXCR3 agonists impairs receptor signaling and lymphocyte chemotaxis, while preserving antiangiogenic properties. Blood 98:3554-3561. 